\title{
COMMENTARY
}

\section{Fixing the leak: targeting the vascular endothelium in sepsis}

\author{
Aaron Spicer' and Carolyn S Calfee ${ }^{2 *}$ \\ See related research by Alfieri et al., http://ccforum.com/content/16/5/R182
}

\begin{abstract}
Angiopoietin-1 is a Tie-2 receptor agonist that stabilizes vascular endothelium, promoting endothelial maturation and preventing capillary leak. Angiopoietin-2 is largely a competitive partial antagonist that is markedly elevated in humans and animal models of sepsis and other inflammatory states, directly disrupts the endothelial barrier, and has been correlated with end-organ dysfunction and death in sepsis. In the previous issue of Critical Care, Alfieri and colleagues used intravital microscopy to study the microvasculature in a murine model of sepsis. Treatment with a modified angiopoietin-1 molecule led to reversal of albumin vascular leak and improved blood flow to skeletal muscle, as well as a decrease in the levels of several inflammatory cytokines. Importantly, the angiopoietin-1 variant was administered 20 hours after initial lipopolysaccharide challenge. This study adds to the evidence that the angiopoietin/Tie-2 axis represents a modifiable pathway through which targeted therapy may be able to directly reverse part of the pathology of sepsis.
\end{abstract}

Despite decades of research and untold investments of time, energy, and money, treatments for sepsis other than antibiotics and supportive care have remained elusive. Over this time, our expanding understanding of the biology of sepsis has led to the development of targeted treatments, including immunomodulatory and anticoagulant approaches, yet so far all of these approaches have been ultimately unsuccessful.

With this historical backdrop, much recent translational research in sepsis has focused on the importance of vascular endothelial permeability, a pathophysiologic

*Correspondence: Carolyn.Calfee@ucsf.edu

2Departments of Anesthesia and Medicine, University of California, San Francisco, San Francisco, CA 94143, USA

Full list of author information is available at the end of the article hallmark of the syndrome and the focus of the work of Alfieri and colleagues in the previous issue of Critical Care [1]. The angiopoietin (Ang)-1/2 axis is a key regulator of endothelial permeability, operating via the Tie-2 receptor on vascular endothelial cells. Ang-1, the primary Tie-2 agonist, decreases capillary leak and inhibits leukocyte-endothelial interaction, among other effects [2-4]. In contrast, Ang-2, produced primarily in endothelial cells, functions as a context-dependent Tie-2 antagonist $[5,6]$. Elegant experimental and translational studies have clearly demonstrated that Ang-2 plays a critical role in the organ injury of sepsis by mediating increased endothelial permeability $[7,8]$. Likewise, clinical studies have identified a strong association between lower Ang-1 and/or higher Ang-2 levels and poor clinical outcomes in sepsis, including acute lung injury, pulmonary leak index, multi-organ dysfunction, and mortality [6,9-11]. Thus, manipulation of the Ang-1/2 axis has become an appealing therapeutic target.

One challenge of therapeutic intervention on the Ang-1/2 axis is that recombinant human Ang-1 has poor solubility and a short half-life [12]. Thus, alternative approaches to effective delivery of Ang-1 have been investigated in experimental models. Cartilage oligomeric matrix protein-angiopoietin-1 (COMP.Ang-1) is a soluble and stabilized variant that binds more avidly to Tie-2 than native Ang-1 [12]. COMP.Ang-1, adenovirusdelivered Ang-1, recombinant human Ang-1, cell-based therapies, and a synthetic Tie-2 agonist all reduce vascular leak and end-organ dysfunction in murine sepsis models [13-19]. Each of these approaches has some appeal; Alfieri and colleagues chose to investigate the effects of a modified Ang-1 molecule, MAT.Ang-1, formed by fusing the coiled-coil domain of human matrilin- 1 to the fibrinogen-like domain of human Ang-1. MAT.Ang-1 has better solubility than recombinant Ang-1 and yet more similar biologic activity to native Ang-1 than COMP.Ang-1 [12].

To study the effects of this modified Ang-1 in experimental models of sepsis, Alfieri and colleagues implanted window chambers into the dorsal skinfolds of mice, so as to visualize skeletal muscle blood flow with laser Doppler 
imaging. Lipopolysaccharide (LPS) was injected intraperitoneally at 0 and 19 hours, followed by intravenous MAT.Ang- 1 at 20 hours. MAT.Ang- 1 returned LPSinduced leak of albumin to control levels at 23 and 24 hours, without affecting vascular permeability in mice untreated with LPS. Microvascular perfusion at 24 hours partially improved in LPS-challenged mice treated with MAT.Ang-1, but did not return to normal. In addition to its effects on vascular permeability and perfusion, MAT. Ang-1 reduced tumor necrosis factor alpha, interferon gamma, triggering receptor expressed on myeloid cells-1, granulocyte colony-stimulating factor, and IL-10 in LPSunchallenged mice, a novel finding given that other studies have not treated well mice with Tie- 2 agonists. LPS-induced elevation in IL-1 $\beta$, IL-10, and IL-1 receptor antagonist was decreased by MAT.Ang-1, consistent with two other Tie-2 agonists' effects on inflammatory cytokines $[14,20]$.

What can we learn from this new study, and how has it advanced the field? First, MAT.Ang-1 was given after the administration of LPS, rather than prophylactically. While the therapeutic interval was short, this treatment model highlights the possibility that a Tie-2 agonist could be a feasible therapy for the microvascular dysfunction of sepsis. Second, although MAT.Ang-1 was described previously, this study represents its first therapeutic trial in this setting. Third, the in vivo imaging of skeletal muscle provides an interesting window into microvascular function and a novel demonstration of the potential therapeutic effects of manipulation of the Ang1/2 axis.

At the same time, many questions about the effects of this modified Ang-1 compound remain unanswered. In the current paper, only effects on skeletal muscle vasculature and expression of cytokines and angiogenic factors were assessed. What might lung intravital microscopy, which has become a valuable scientific tool in models of acute lung injury, reveal about the effects of MAT.Ang-1 on the pulmonary vascular bed and leukocyte trafficking in the lung? More broadly, what are the effects of MAT.Ang- 1 on organ injury and mortality in experimental models of sepsis? How does MAT.Ang-1 affect the immune response, including bacterial counts, in live bacterial models? Perhaps most importantly, how do different approaches to manipulating the Ang-1/2 axis compare in the same experimental sepsis models?

While many questions remain, this work by Alfieri and colleagues adds to the growing weight of literature highlighting the potential value of targeting the vascular endothelium in sepsis and will certainly pique the interest of the many researchers who are continuing the decadeslong quest for the holy grail of a targeted sepsis therapy.

\section{Abbreviations}

Ang, angiopoietin; COMP.Ang-1, cartilage oligomeric matrix proteinangiopoietin-1; IL, interleukin; LPS, lipopolysaccharide.

\section{Competing interests}

CSC receives research funding from the National Institutes of Health, the Flight Attendant Medical Research Institute, and Glaxo Smith Kline and has served on medical advisory boards for Ikaria, Cerus Corporation, and Glaxo Smith Kline.

\section{Acknowledgements}

Funding: NIH/NHLBI HL090833 and HL110969 (CSC).

\section{Author details}

'Department of Pediatrics, University of California, San Francisco, San Francisco, CA 94143, USA. ²Departments of Anesthesia and Medicine, University of California, San Francisco, San Francisco, CA 94143, USA.

\section{Published: 21 November 2012}

\section{References}

1. Alfieri A, Watson JJ, Kammerer RA, Tasab M, Progias P, Reeves K, Brown NJ, Brookes ZL: Angiopoietin-1 variant reduces LPS-induced microvascular dysfunction in a murine model of sepsis. Crit Care 2012, 16:R182.

2. Hirschberg R, Wang S, Mitu GM: Functional symbiosis between endothelium and epithelial cells in glomeruli. Cell Tissue Res 2008, 331:485-493.

3. Neagoe PE, Brkovic A, Hajjar F, Sirois MG: Expression and release of angiopoietin-1 from human neutrophils: intracellular mechanisms. Growth Factors 2009, 27:335-344.

4. Dumas E, Martel C, Neagoe PE, Bonnefoy A, Sirois MG: Angiopoietin-1 but not angiopoietin-2 promotes neutrophil viability: Role of interleukin-8 and platelet-activating factor. Biochim Biophys Acta 2012, 1823:358-367.

5. Yuan HT, Khankin EV, Karumanchi SA, Parikh SM: Angiopoietin 2 is a partial agonist/antagonist of Tie2 signaling in the endothelium. Mol Cell Bio/ 2009, 29:2011-2022.

6. David S, Mukherjee A, Ghosh CC, Yano M, Khankin EV, Wenger JB, Karumanchi SA, Shapiro NI, Parikh SM: Angiopoietin-2 may contribute to multiorgan dysfunction and death in sepsis. Crit Care Med 2012, 40:3034-3041.

7. Parikh SM, Mammoto T, Schultz A, Yuan HT, Christiani D, Karumanchi SA, Sukhatme VP: Excess circulating angiopoietin-2 may contribute to pulmonary vascular leak in sepsis in humans. PLoS Med 2006, 3:e46.

8. Davis JS, Yeo TW, Piera KA, Woodberry T, Celermajer DS, Stephens DP, Anstey NM: Angiopoietin-2 is increased in sepsis and inversely associated with nitric oxide-dependent microvascular reactivity. Crit Care 2010, 14:R89.

9. Kumpers P, Lukasz A, David S, Horn R, Hafer C, Faulhaber-Walter R, Fliser D, Haller $\mathrm{H}$, Kielstein JT: Excess circulating angiopoietin-2 is a strong predictor of mortality in critically ill medical patients. Crit Care 2008, 12:R147.

10. Calfee CS, Gallagher D, Abbott J, Thompson BT, Matthay MA, NHLBI ARDS Network: Plasma angiopoietin-2 in clinical acute lung injury: prognostic and pathogenetic significance. Crit Care Med 2012, 40:1731-1737.

11. Ricciuto DR, dos Santos CC, Hawkes M, Toltl LJ, Conroy AL, Rajwans N, Lafferty El, Cook DJ, Fox-Robichaud A, Kahnamoui K, Kain KC, Liaw PC, Liles WC: Angiopoietin- 1 and angiopoietin-2 as clinically informative prognostic biomarkers of morbidity and mortality in severe sepsis. Crit Care Med 2011, 39:702-710.

12. Cho CH, Kammerer RA, Lee HJ, Steinmetz MO, Ryu YS, Lee SH, Yasunaga K, Kim KT, Kim I, Choi HH, Kim W, Kim SH, Park SK, Lee GM, Koh GY: COMP-Ang1: a designed angiopoietin-1 variant with nonleaky angiogenic activity. ProC Natl Acad Sci U S A 2004, 101:5547-5552.

13. David S, Park JK, Meurs M, Zijlstra JG, Koenecke C, Schrimpf C, Shushakova N, Gueler F, Haller H, Kumpers P: Acute administration of recombinant Angiopoietin-1 ameliorates multiple-organ dysfunction syndrome and improves survival in murine sepsis. Cytokine 2011, 55:251-259.

14. Kumpers P, Gueler F, David S, Slyke PV, Dumont DJ, Park JK, Bockmeyer CL, Parikh SM, Pavenstadt H, Haller H, Shushakova N: The synthetic Tie2 agonist peptide vasculotide protects against vascular leakage and reduces mortality in murine abdominal sepsis. Crit Care 2011, 15:R261.

15. Hwang JA, Lee EH, Lee SD, Park JB, Jeon BH, Cho CH: COMP-Ang1 ameliorates leukocyte adhesion and reinforces endothelial tight junctions during endotoxemia. Biochem Biophys Res Commun 2009, 381:592-596.

16. Kim DH, Jung YJ, Lee AS, Lee S, Kang KP, Lee TH, Lee SY, Jang KY, Moon WS, Choi KS, Yoon KH, Sung MJ, Park SK, Kim W: COMP-angiopoietin-1 decreases lipopolysaccharide-induced acute kidney injury. Kidney Int 2009, 76:1180-1191. 
17. Witzenbichler B, Westermann D, Knueppel S, Schultheiss HP, Tschope C: Protective role of angiopoietin-1 in endotoxic shock. Circulation 2005, 111:97-105.

18. Huang YQ, Sauthoff H, Herscovici P, Pipiya T, Cheng J, Heitner S, Szentirmai O, Carter B, Hay JG: Angiopoietin-1 increases survival and reduces the development of lung edema induced by endotoxin administration in a murine model of acute lung injury. Crit Care Med 2008, 36:262-267.

19. McCarter SD, Mei SH, Lai PF, Zhang QW, Parker CH, Suen RS, Hood RD, Zhao YD, Deng Y, Han RN, Dumont DJ, Stewart DJ: Cell-based angiopoietin-1 gene therapy for acute lung injury. Am J Respir Crit Care Med 2007, 175:1014-1026.
20. Mei SH, McCarter SD, Deng Y, Parker CH, Liles WC, Stewart DJ: Prevention of LPS-induced acute lung injury in mice by mesenchymal stem cells overexpressing angiopoietin 1. PLoS Med 2007, 4:e269.

doi:10.1186/cc11829

Cite this article as: Spicer A, Calfee CS: Fixing the leak: targeting the

vascular endothelium in sepsis. Critical Care 2012, 16:177. 